\title{
Biologic Entity Identifier Type Code
}

National Cancer Institute

\section{Source}

National Cancer Institute. Biologic Entity Identifier Type Code. NCI Thesaurus. Code C93745.

A coded value specifying the kind of biologic entity identifier. 